\title{
HOW IS ICT SHAPING THE REFUGEE GOVERNANCE LANDSCAPE IN TRANSITIONAL BANGLADESH?
}

\author{
A. N. M. Zakir Hossain ${ }^{1}$
}

DOI: 10.24989/ocg.338.16

\begin{abstract}
The information communication technology (ICT) has a great impact in shaping life and responses. The current century is running with the rampage of cutting edge technologies that compose our everyday life while the expansion of ICT allows us to make our life meaningful. The most significant challenges in transition are to coping with the changes that even happen all of a sudden i.e., about one million refugee influx in Bangladesh in 2018. Nowadays people recognized ICT as a decisive and inseparable part of them that constructs a new fashion of modern democratic governance. Though ICT is crucial in representative governance but now it inflates both the magnitude and persuade. The study tries to treat them embedded in the governance nexus and connected to each other. The present study focuses on the nexus between ICT and refugee management which shaped the refugee governance landscape in transitional Bangladesh. The endeavor of the study is to answer the questions on how ICT and administration act and react with each other on the refugee governance issues and how it indicates the future role of administration in refugee management and resettlement. The study followed the content analysis method and primarily based on secondary sources of data to reach the inferences. The results found ICT as a comprehensive platform that includes the different stakeholders and emphasized the trade-off between them which in our case Rohingya refugees governance. It provides geo-localized support for them and specific aid during the adverse situation. It is also found that it helps the administration to identify the synchronized ideas of people that coordinate their actions to produce services for the people. The study concludes by arguing for the management and wrapping of multidimensional data through the observatory mechanism that could likely develop their life and incentives required for the administration to act in support of the governance and resettlement of refugees in the future.
\end{abstract}

\section{Introduction}

"In the world, we live in today, internet connectivity and smartphones can become a lifeline for refugees. -Filippo Grandi”

The refugee explosion all over the world has become a tough challenge for the world community. The number of refugees has amplified significantly because of armed conflicts in several parts of the world. The recent refugee phenomenon has become a global problem, and the resettlement of these refugees has become a central topic among world leaders. According to the current report of the United Nations High Commissioner for Refugee (UNHCR), the amount of forcibly displaced persons is 70.8 million, where 25.9 million refugees, 41.3 internally displaced people, 3.5 asylum seekers as a result of persecution, conflict, violence, or human rights violations at end-2018. Among them, only

\footnotetext{
${ }^{1}$ A N M Zakir Hossain, Ph.D. Research Fellow, Doctoral School of Public Administration Sciences, National University of Public Service, 1083 Budapest, Hungary and Faculty of Bangladesh Agricultural University, Mymensingh-2202, Bangladesh. Email: anmzakirhossain@bau.edu.bd
} 
20.4 million refugees under UNHCR's mandate (UNHCR, 2019). As in 2018, more than two-thirds of the world's refugees are from just five countries: Syria, Afghanistan, South Sudan, Myanmar, and Somalia. According to the UNHCR (2018), Turkey hosts the largest number of refugees 3.7 million, Pakistan 1.4 million, 1.2 Uganda, Germany 1.06 million while the fourth-largest number of refugees by country of origin persisted steadily at 1.1 million from Myanmar and Bangladesh continued to host a large population of 906,600 refugees at the end of 2018, almost entirely from Myanmar.

It is pertinent that they are protected and treated humanely, where they take refuge. The refugee issue has been a sensitive subject for states because states that cause refugee problems perceived as those that are intolerant of racial, religious, or linguistic minorities. Rohingya refugees faced an uncertain future with a lot of violations and vulnerabilities that ultimately made them stateless and fallen them in an identity crisis. Refugees who are in camps, not allowed for "legal protections enshrined in international, regional, and domestic laws" (Holzer, 2013) as they are waiting for relocating.

International and local (recognized) humanitarian organizations and NGOs are intervening ICT based services in the refugee camps all over the world (Mason and Buchmann, 2016). The present study focuses on the nexus between ICT and refugee management, which shaped the refugee settlement landscape in Bangladesh. The study tries to treat them embedded in the governance nexus and connected to each other, especially the refugee tragedy. There's a widespread consensus that there is a lack of policy in the countries that make up the resettlement of Rohingya refugees. The endeavor of the study is to answer the questions on how ICT and refugees are responding with each other in this crisis and create an impact in this context. In our present study, we tried to figure out how Information and Communication Technology (ICT) is complementing the refugees in their distressing trip to safety from their homeland to the host country, the transitory settlement at the camps, and post-inclusion at the host country.

\section{ICT, Refugee Status, and Livelihoods}

Information and Communication Technology (ICT) is one of the major driving forces of the current world economy, polity, and governance. This is factual for human mobility; services, identification, and status are given for rights and opportunities all over the world. The present world has witnessed an ocean of displaced people after World War II. Refugees are more and more connected, accessible to people from outside, and more and more IT services by the agencies. ICT is helping several ways in refugee management all over the world. The formal human mobility depends on their nationality and status, which comprise their economic viability and choices and the acceptability of the host country. But it does not even work for the people who are forced to flee from the place of origin where they born, grown, and lived. These people are going to lose the formal identity that helped them to prove their national identity to move a formal and legal way.

Refugee status is not a simple one and not given to a person without any formal procedures. Once a person would like to get the status, it requires a formal appeal or application, then the host authority investigates that issue and the contemporary situations for providing him/her the refugee status. In this process, the host country or authorized body can use the ICT from investigation to the decision level to make a formal decision about the refugee status.

ICT enabled biometric helps the procedure to define a status about a person as he/she requires and demands. When any person has given the refugee status or not given before/after the process, a simple biometric registration helps the hosting authority to secure and smoothen the procedures. Through this biometric registration, it is easy to use and manage the data of a respective person for further 
utilization. The process of biometric registration is a simple way to collect the necessary information of a person through a computer and biometric machine and easy to provide him a service-based registration number, based on these data, and getting the benefits for them. Most of the cases the service is food, basic medical service, and some house-holds products that are daily needed for their livelihoods at the camps. The refugee data are fragmented, and there are two different ways that information is flowing and being captured; i. refugees themselves create data sets and ii. sack the data. Refugees themselves create a database by using different social media, i.e., Facebook, whatsapp, twitter, phone call, Instagram, snap chat, etc. They create their media data. Now the question is why we all do need this because of a beautiful marriage between control and it.

These people have given a mobile phone and SIM (subscriber identification module) card that grants access to the internet for available information that required for their livelihoods in the camp also for health service through SMS or phone call. Also, potentially some control over the connectivity, people who are connected, funding cards, etc. In Jordan for refugees, they initiated eye scanning instead of the card, which made it easy to manage them in every sphere of the movements of the refugees, including service providing. World Food Program (WFP) and Jordan shared this biometric data to the World Health Organization (WHO) benefits. These data also help to improve the accountability of the organizations that are deployed in refugee camps for programs. The digital refugee is jointly constructed persona, each refugee has their own story that they are putting into cyberspace, not all, but many and control the narratives of this part of the story, not always, not largely order their control. But the implication and threat to the security of the data and refugees are how are you going to manage the data, where the data is going, what has the rights of the cloud, who takes ownership of that data, refugee policies significantly vary from country to country.

\section{Rohingya: When and How Come into Bangladesh as Refugee}

The refugees have become helpless victims, not of their own making. It is pertinent that they are protected and treated humanely in countries where they take refuge. As armed conflict caused a massive flow of refugees, the issue of refugees, in turn, may lead to tensions and conflicts between states. The issue of the refugee has been a sensitive subject for states because states that cause refugee problems perceived as those that are intolerant of racial, religious, or linguistic minorities. For instance, Bangladesh intakes a large number of Rohingya Muslim refugees during the crisis periods, but when the ethnic cleansing started at Rakhine last year, the figure amounted to total of 918,936. In recent times, one can hardly find a government that has been so dreadful, so brutal, and so barbarous in its refutation of fundamental human rights to a people that trace their origin to the land for nearly a millennium.

The Rohingya Muslims are the victims, living in the Arakan (now Rakhine) state, and become the forgotten people of our time (Siddiqui, 2018, Ahsan Ullah, 2016, Leider, 2018). About 40 percent of the Rakhine population is Muslims who fled to Bangladesh from Myanmar when the ethnic cleansing started decades ago. That considered as "a semi-organized social movement with clear political goals" (Klinken \& Aung, 2017). However Rohingya people were in a realm of statelessness for over six generations (Milton and Rahman, et al., 2017).

The political landscape in Myanmar was founded through the British colonial period; (Kipgen, 2016). It is necessary to know why the alienation of Rohingya started (Knuters, 2018) because of the 


\section{How Myanmar expelled the majority of its Rohingya to Bangladesh}

After the recent influx of a half-million Rohingya into Bangladesh, the country now hosts more Rohingya than Myanmar.

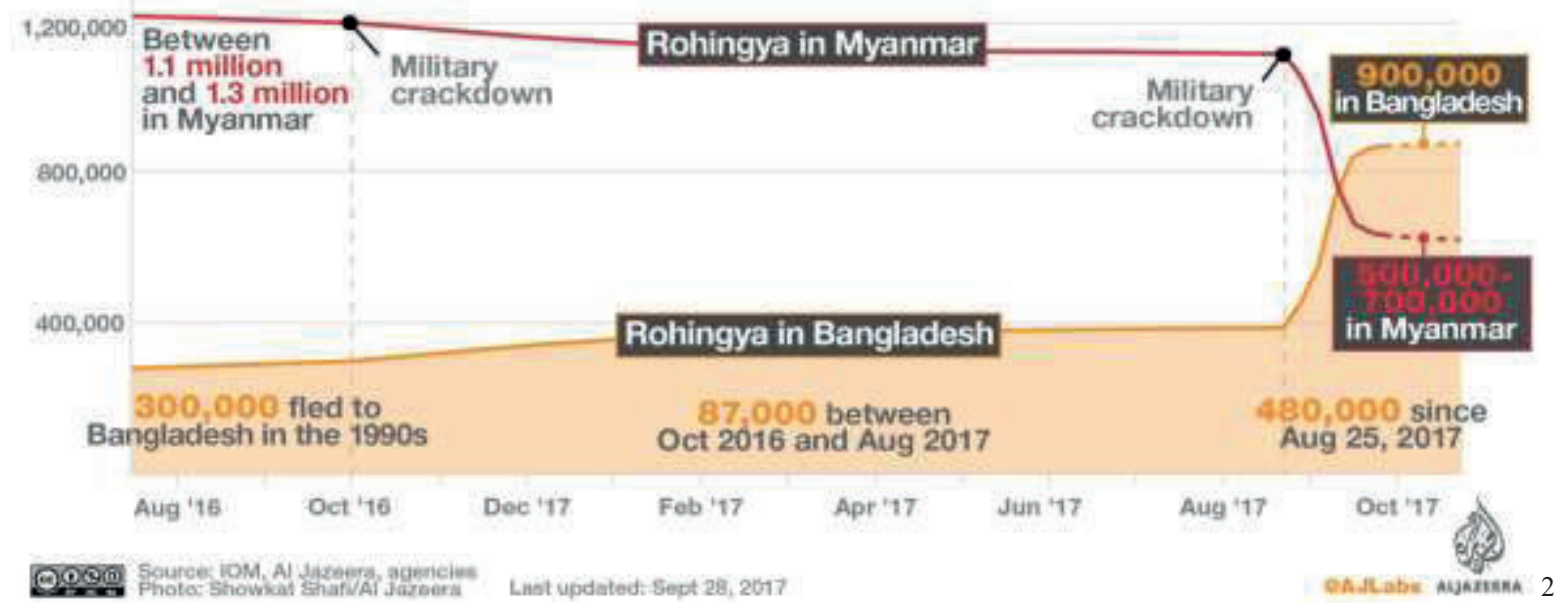

Figure 1: Rohingya Refugee from Myanmar to Bangladesh

Rohingya refugee sites in Bangladesh

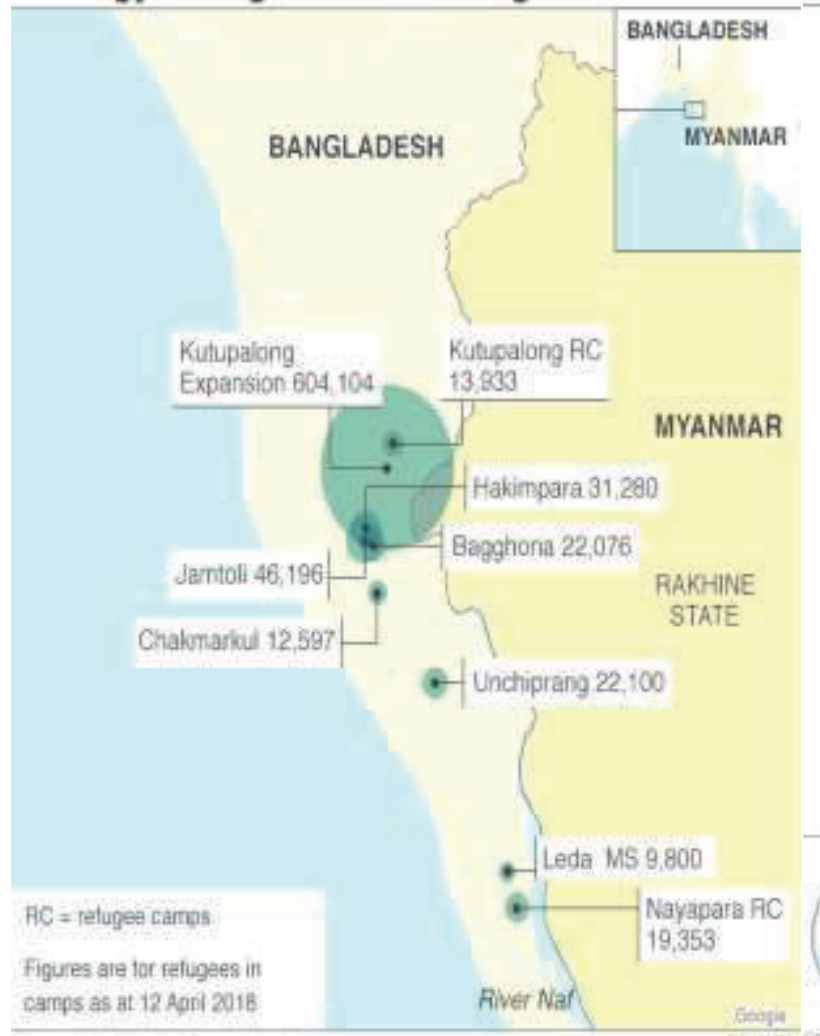

Destroyed villages in Rakhine state

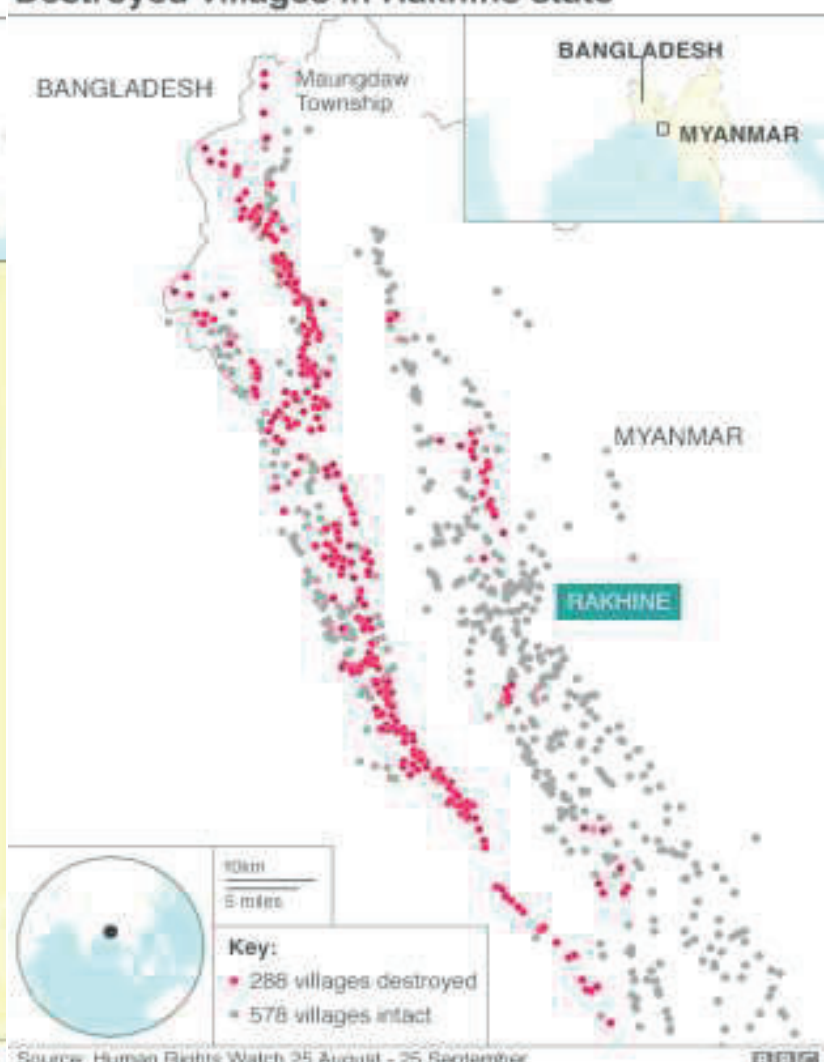

Figure 2: Destroyed Villages in Rakhine and Refugee sites in Bangladesh

${ }^{2}$ https://www.statista.com/chart/16109/who-are-the-rohingya-refugees-in-bangladesh/ 
trust of authority towards a rebellious minority was low and vice versa due to the role of British in the colonial period as they used different minor groups against ethnic Burmans. Each and every state has a historical background of its own and has had an influence of colonizing nations, which combines both general ideology and particular policies to format general and economic ideology (Johnson, 1967). Counter-modernization movement's results-religious, linguistic groups rebel and demand a return to fundamentalism (Hoselitz, 1961). However, secularization is a process, transition from prescriptive to principle society and does not mean that religion disappears.

The oppression towards Rohingya was brutal and turned into genocide and this brutality amount to a vulgar violation of their human rights (Knuters, 2018) in Myanmar. As Myanmar governments have estranged Rohingya through nationalistic and religious policies, the study is to uncover the role of ICT in the governance of refugees.

\section{Refugee and ICT- Global Depiction}

The world has witnessed an enormous number of people than ever after World War II. About 250 million of migrants all over the world 60 million are refugees. According to the reports that has been published by different research and human rights organizations around the world put pressure on the issue that "refugee crisis" is only the problem of middle eastern and European countries are facing enormous challenges due to refugee influx however the numbers of refugees are hosted by many developing countries of the world. The refugee crisis is well known due to the scale of human tragedy and public awareness with massive media coverage. Overall, more than 134 million people across the world need humanitarian assistance and protection - and more funding than ever before (Human Rights Watch, 2019). According to the report of the Financial Tracking system, about 135.3 million people need humanitarian support while in 2009, the fund required USD 9 billion for assistance but received only the USD 7 billion. When we are talking about the year 2018, the fund required USD 25.2 billion and received only USD 14.6 billion (OCHA, 2019), and this gap widens gradually and creating risk and anxiety to the leaders of the world in the coming future.

Global and local actors, including GOs, NGOs, and other humanitarian organizations are working together as a team to respond to the issue of refugees to support them from different stripes. Information and communication technology are working a significant role in this digital era of technology during their journey from citizens to become a refugee. A smart mobile phone is an integral piece of kit for millions of refugees as they are moving one to another place. ICT provides compliance to refugees for social inclusion that favorable to empowerment "to fully participate in society and control their own destinies" (Warschauer, 2003).

The global mobile phone is sort changing the landscape of technology and development, so, the phrasing of mobile having to reproduce the technological reproduction of the 21 st century is pretty popular and by common and definitely applies to serve like refugee camps where people have to settle down, communities have sort developed their infrastructure needed for like LAN line, computer laboratory, mobile phone, etc. In 2016 United Nations High Commissioner for Refugees (UNHCR), connecting refugees, how the internet and mobile call connectivity can improve refugee well-being and transform humanitarian action, and they reported 93 percent refugees to have access to some level of digital and mobile access.

Filippo Grandi, the United Nations High Commissioner for Refugees said "Most importantly, connectivity can help broaden the opportunities for refugees to improve their own lives and pursue a vision of a future that would otherwise be denied to them" and "Most importantly, connectivity can 
help broaden the opportunities for refugees to improve their own lives and pursue a vision of a future that would otherwise be denied to them".

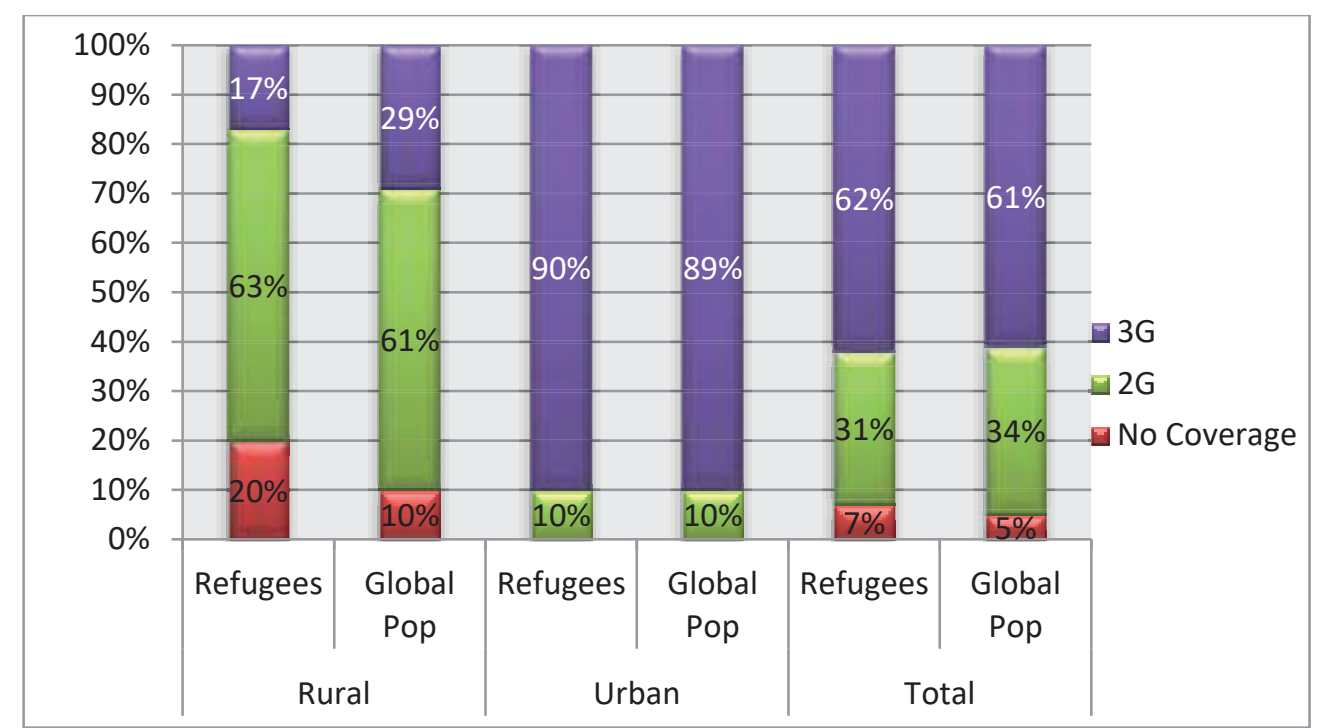

Figure 3: Refugees vs. Global Population: Mobile Network Coverage (UNHCR, 2016)

"Refugees deem connectivity to be a critical survival tool in their daily lives and are willing to make large sacrifices to get and stay connected" (UNHCR, 2016, p-15).

According to the report published by UNHCR in 2016 revealed that mobile phone and internet access is worth, not only to connect with loved ones, but also for their safety and security like food, shelter, and water. The study also found that access to mobile phone depends on the affordability while refugees are in urban parts tend to have parallel access to mobile like other urban peoples. But for them who are in the rural region, the scenario is very unlike. Where only one has mobile in five and one has $3 \mathrm{G}$ access in six that is considerably lower for them at large. The findings originated at a moment while the world witnessed an enormous number of people who are driven by war and persecution than any time of world history. At the end of 2018, 70.8 million people were globally displaced, of whom 2-9 million were a refugee. Confronted by the persistent need, the results of the study suggested further investments in three key areas, which composed the basis of a new UNHCR Global Strategy for Connectivity for Refugees. These comprise i. increasing the accessibility of mobile networks, ii. improving affordability and iii. providing access to training, digital content, and services (UNHCR, 2016).

People are rural settings also have some access to internet connectivity to some degree, and costs and barriers surprising. UNHCR identifies a significant portion (two-third) of financial resources available to many refugees are being spent to call and the call stays connected. So that sort of helps the landscape what is happening many of these communities. So, all these represent a landscape portion possibility and an opportunity for development cross-different sector. This relevant to help the education to security and also opens to the door to the conservation about the changing fabric of these place's communities to the society that performing across the migratory journeys and the cultural norms and practices that are emerging and intend them within an across the technological landscape. However, there are still a few challenges that still exist among the refugees, i.e., literacy on technology, access, and usages (Mason and Buchmann, 2016). 


\section{Refugee and ICT- Bangladesh Depiction}

\subsection{Refugee and Food Security: Role of ICT}

The refugee influx in 2017 generates a perilous situation for both the refugee and the government of Bangladesh. Bangladesh is facing several challenges to uplift the economy from developing one to middle income with steady economic growth. With the development of a multi-dimensional aspect, we have to move forward concerning many aspects to ensure the well-being of the citizen of Bangladesh. Though Bangladesh is now self-sufficient in food production still there is a limitation to equal distributions of income and foods. The refuge fled from Myanmar is in a hazardous and unsafe condition even in Bangladesh at that time due to food, shelter, and security. Refugees are found vulnerable and exclusively dependent on humanitarian assistance (REVA-2). Influx reduces the scope of income generation for unskilled labors in a highly competitive labor market that leads them for external aid for main income.

World Food Program (WFP) and Food and Agriculture Organization (FAO) are leading, along with about 30, other national and international organizations to ensure the food security for the refugees. More than 880000 people are directly connected within the general food service that is provided in 34 refugee camps. However, the unregistered refugees are found most vulnerable who came before influx (WFP, REVA-2, 2018). The food service is providing by in-kind or e-voucher and complementary food items. About 65\% of refuges at the end of March 2019 are now under e-voucher service. Though in-kind foods are life-saving, for diversified diets, an e-voucher is programmed to be implemented within December 2019 while they also need fuel, health, light/electricity, and access to safe drinking water, which are also crucial (NPM 13, 2018).

The following baskets of in-kind food items are distributed two cycle per-month from 19 scattered points of distribution through 32 camps.

\begin{tabular}{|l|l|}
\hline Family Size and Persons & Number of Basket* Receive \\
\hline Small Size (1-3) Persons & One Basket \\
\hline Medium Size (4-7) Persons & Two Baskets \\
\hline Large Size (8-11) Persons & Three Baskets \\
\hline Very large Size (11+ Persons) & Four Baskets \\
\hline
\end{tabular}

Table 1: Different Family size and received items

* One Basket=Rice 30Kg, Pluses 9 Kg, Fortified Vegetable Oil 3 Litre

WFP is, with the cooperation of a range of food security partners, trying to enhance the dietary diversity for most vulnerable people like children up to 5, elderly, disabled people, pregnant, people with chronic illness and lactating mothers who are getting in-kind blanket food assistance complemented by vouchers for fresh food items i.e., fish, egg, vegetables, and spice. WFP has planned, through a biometric debit card, to transform all the refugees from in-kind food assistance to e-voucher. A refugee can use the debit card (SCOPE) to have a range of food items from private shops contracted by WFP while the debit cards are monthly credited.

There are 10 e-voucher outlets, which will be increased to 21 at the end of 2019, and 24 shops while one is for 5000 to 20000 households for seven camps. To ensure the diversity of food and nutritional security, they have been offered twenty food items, among them twelve compulsory items are given at a fixed price, set before by negotiation, and eight flexible items traders sold by choice. 


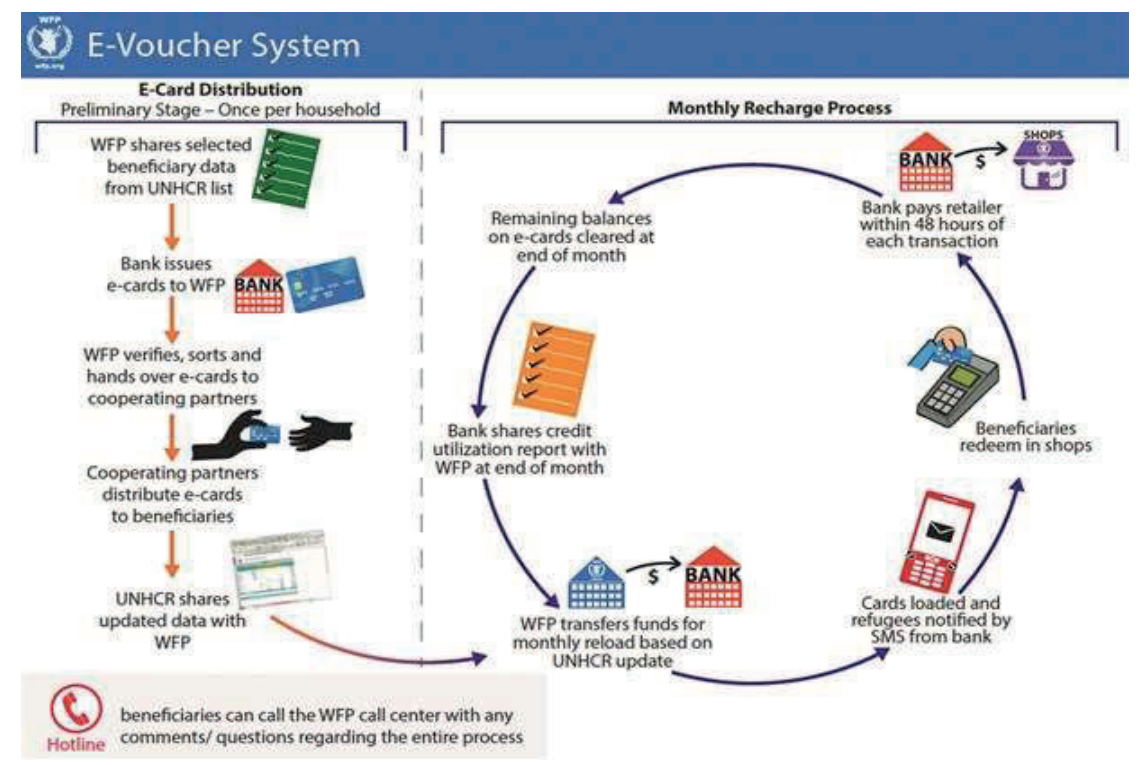

Figure 4: E-Voucher System

\subsection{Technology in Gender and Development:}

ICTs in development in refugee camps and thinking about gender has a pretty sort of the top level in these structures. We are aware of the role of mobile phones and sort of changing the landscape of technology and development so the phrasing of mobile phones having leapfrogged being the technological leapfrog of the 21 st century pretty popular and quite common. ICT also contributes to greater refugee empowerment of mobile-based technology, especially using social media (Andrade and Doolin, 2015), and other purposes also help the governaning process on the refugee camps. A senior woman of a family was given the SCOPE card issued by the WFP, but the control and use of the card implemented by the male person and entire decision are made by the male, still, women are struggling to be empowered within the house-hold decision making(UNHCR-WFP, 2019). The REVA-2 reveals the prevailing precarious circumstances surrounding the refugees: the absence of resources and inadequate income generating opportunities degrades their situation further. Overall, food related coping has improved during 2018 and -is found to be more dominant among newly arrived refugees as compared to the registered refugees (WFP:REVA-2, 2018). "Offline constraints and incentives still appear to frame the nature of online interaction much more than generally acknowledged and it is, therefore, important to see and understand the realities of marginalization in which internet use is embedded and complex tapestry of a socio-economic crisis that frames it (Iwilade, 2015).”

\subsection{Migration Integration Governance and Justice in Refugee Camp}

The Government of Bangladesh (GoB) is always respectful of international human rights law and treaties all along. They also showed their generosity in every aspect of national and international human rights issues. Bangladesh is not familiar with the refugee issue; however, it had started to receive Rohingya after its independence, but this turn into a dramatic one in 2017 when the persecution and ethnic cleansing started at Rakhine state by the Myanmar government.

The latest beckon of aggression was termed as "ethnic cleansing" (OHCHR, 2017), however, triggered the massive Rohingya refugees influx in Bangladesh and many of them are biometrically redistricted and given identity cards by the Immigration and Passport Department of Bangladesh (Oh, 2017) and providing-shelter, relief and medical service (Khatun and Kamruzzaman, 2018). However, 
with the cooperation of local and global agencies government respond to the crisis, but it is evident that contemporary life-saving funding is not sustainable and sufficient for programming and humanitarian actions. It is crucial to initiate a more development-oriented approach; to build the national resilience and sustain the degree and value of service delivered (Mason and Buchmann, 2016).

It was the largest human displacement in the 21 st century in that region. Bangladesh has done a tremendous success in immediate scale-up, and partnership with other humanitarian organization and community, to deliver support and shield for saving the life of the refugees (UNHCR-WFP, 2019). Refugees are governed, including habitation and movement by the Foreigners Act of 1946 (Article 3) because Bangladesh neither a countersigned of the 1951 Refugee Convention nor the 1967 Protocol concerning the Status of Refugees and does not have a refugee law. Foreigners Act empowered the Government to retain them in prescribed place and execute movement restrictions on them until they obtain permission to travel, mentioning the valid reason. Refugees are allowed to go outside of the cams to doctors and courts with prior approval by camp administrators (CICs).

Bangladesh sang in different global human rights treaties that indirectly support the Rohingya refugees in humanitarian aspects; however, there is a limitation that they are not enforceable in a local court by domestic law for their misconduct that made questions in the issue of local security (Khatun and Kamruzzaman, 2018).

\subsection{ICT and Refugee Family Unification}

The Ministry of Home Affairs of the GoB conducted a biometric registration of the refugees who had been here and were undocumented before the incursion and the new arrival who came in 2017 . The process ended in June 2018 and registered 1.2 million refugees have been given an individual MOHA card. The primary challenge was the missing link between the individuals and his/her family members that were crucial for assistance at the household level.

UNHCR has started to complement MOHA's registration, in association with Refugee, Relief \& Repatriation Commissioner (RRRC), for support and shield purposes and to tie every individual to a family. In March 2018, 876000 persons and/or 203407 households had been calculated and connected to a family and was given a Family Card with a Family Counting Number (FCN) when their housings were geotagged (UNHCR-WFP, 2019). However, later these cards (MOHA and FCN) has been replaced by a Smart Card with a household ID number when MoHA and UNHCR started a combined registration in June 2018 at five registration sites, where previous registration took place, for updating biodata and biometrics for the next three years including iris scan to amalgamate and modify some of the adequacies of earlier registration. Already 43 percent refugee people are registered under these by the end of June 2019, which is equal to 374,000 persons and 82,000 refugee households.

Once officially registered, refugees receive a Smart Card with a household identification to replace both, the MOHA and FCN card. As of 30 June 2019, about 43 percent of the refugee population had been officially registered, the equivalent of about 374,000 individual refugees and 82,000 refugee households (UNHCR-WFP, 2019). It is also evident that the use of social media like Whatsapp, and/or Facebook messenger, in a new society mostly used by refugees, as an efficient, cost effective and favorite due to easy access to communicate with their family members, relatives and get back home (Vernon, Deriche, and Eisenhauer, 2016, and AbuJarour \& Krasnova, 2017). 


\subsection{Refugee, Terrorism and Homeland Security Governance of Bangladesh}

The concept of terrorism identified that the terrorist has had a clear goal for every attack that they performed. It is also found that they believed in violence to coerce the polity to change as do not like the current institutional structure of the existing society. However, they claimed they do not have any alternative choice. Techfugees is an umbrella organization that works on refugee-related issues, Mike Butcher in September 2015 developed this. It has created a novel media landscape and became a central site for those working in networking and exchange in the site.

There is a focus on the ICT that conducive for receiving and supporting refugees who are fled from their homeland and living in a camp in the host country. ICT refers to a digital device and systems which are accessible to everyone. The main technology that used, for information and communication technology, by the refugee is the internet because it is cheap and easy to access. ICT is crucial for them during their distress journey from home to the host country. It also enables them to maintain contact with their relatives and stabilize a degree of their insecure and uncertain situation (Mason and Buchmann, 2016).

The most serious issue is that as the refugees are not supposed to have any job in the law of the land of the host country but they have given free food and many basic items that even not available to the host community. In this process, their consume habit was changed without any income generating behaviors; however, its humanitarian issue after all. Through this way, the lifestyle that they are enjoying it will be heartened that they don't want to lose and try to maintain at any means that crate threat to host country due to the funding crisis can create an unstable situation where we need to take several initiatives for integration resettlement and repatriation. However, ICT based identification is a strong mechanism to trace and track anybody if he/she create any threat to the host community and country as well as refugees.

\subsection{ICT for Sensitization or Understanding the Education and Languages}

Information and Communication Technology (ICT) for Development is a new avenue and creates a new eco-system that combines ICT and development theory to expedited the speed, intensity, and diversity of this arena that wasn't ever before. ICT plays a decisive role in educating refugees and access to the various resources of languages. Education on (local) languages is a key to communicate with the local groups, officials, and others to people during the journey of a refugee. It also helps them to maintain their daily life in a hosting country. Education through ICT also helps them to participate in further educational programs that help them in their daily life to be asylum seeks or to resettle elsewhere. To overcome the challenges of accessibility on education and other basic services has alleviated by the intervention of ICT for refugees in different parts of the world (AbuJarour \& Krasnova, 2018). However, it is valuable to provide electronic educational materials but inadequate without inclusive teaching support (Dahya, 2016) to achieve the ultimate goal of the refuge.

\subsection{ICT for Consolidation System and the Work of NGOs}

Refugee camps are the places where the situations are changing in every moment for several reasons. ICT can be helpful for a place where the situations are changing rapidly and to capture the needs of the targeted people that easily shape the governance landscape. NGOs are using different software that helping them to organize their work more effectively and promoting accountability in service delivery. They use many devices, i.e., mobile, tablets to conduct their assessment survey, evaluating and processing the responses, and sharing with other humanitarian local and international 
organizations that can be helpful for refugees and for them to arrange and deliver the services. It is also helpful for the bodies who are working in that area to respond to the needs and demands of the refugees. Whatsapp, imo, viber, and/or facebook messenger also useful tools for the volunteers, workers to track them to each other during the process of any new service of product delivery in the refugee camps.

\section{Conclusion}

The government of developing countries still has several challenges that they are facing during their transition concerning social, economic, and political. Bangladesh is running smoothly, from the last decade, with steady economic growth in the way to middle-income country albeit crisis is there. Rohingya refugee has appeared a serious crisis while Bangladesh itself a high densely populated country of the world. Due to the global and regional refugee crisis, we discuss the role of ICT in refugee governance as most of the refugee is hosted by the developing countries. Research on the governance of refugees can help to develop a way to find the management and solution of the crisis that the refugee and host countries are facing. Governance of refugees can also be complemented by researchers to work on the different contexts and perspectives to identify the characteristics that can inter-play between technology and refugee to advise a solution to the existing social problems. ICT based service management equipped the regional and global humanitarian organization to become effective and efficient in their service delivery with transparency and accountability. However, there are a lot of challenges in ICT- education, training, outreach, trust, and data protection but working with an existing structure, increase tech access; responsible data practice and collaboration with the different stakeholders and groups can overcome the crisis and complement effective governance of refugees in a country that has no such previous experience.

\section{References}

[1] ABUJAROUR, S. and KRASNOVA, H., Understanding the role of ICTs in promoting social inclusion: The case of Syrian refugees in Germany, In Proceedings of the European Conference on Information, 2017.

[2] ABUJAROUR, S. and KRASNOVA, H., E-Learning as a means of social inclusion: The case of Syrian refugees in Germany. In Proceedings of the Americas Conference on Information Systems, 2018.

[3] AHSAN, U., A.K.M. "Rohingya Crisis in Myanmar: Seeking Justice for the 'Stateless', Journal of Contemporary Criminal Justice. Vol. 32, No. 3, pp. 285-301, 2016.

[4] ANDRADE, A. D. and DOOLIN, B., Information and Communication Technology and the Social Inclusion of Refugees, MIS Quarterly, (40: 2) pp. 405-416. 2016.

[5] DAHYA, N., Education in Crisis and Conflict: How Can Technology Make a Difference - A Landscape Review, 2016.

[6] HOLZER, E., "What happens to law in a refugee camp?." Law \& Society Review 47.4 (2013): 837-872. 
[7] HOSELITZ, B., Tradition, Values and Socio-Economic Development, Duke University Commonwealth Study Center, p 90-113, 1961.

[8] IWILADE, A., New Spaces, New Interactions? Young People's Online Social Networks and Gender Relations in Africa, Gender, Technology and Development, 19:1, 7090, 2015, DOI: 10.1177/0971852414561613

[9] JOHNSON, H. G., The Ideology of Economic Policy in New States" in Harry G. Johnson (ed.) Economic Nationalism in Old and New States Chicago, University of Chicago Press. pp. 124$141,1967$.

[10] KHATUN, F. and KAMRUZZAMAN, M., Fiscal Implications of Rohingya Crisis for Bangladesh, Center for Policy Dialogue (CPD), 2018.

[11] KIPGEN, N., Myanmar: a political history. Oxford University Press, 2016.

[12] KLINKEN, G. van, AUnG, S.M.T., The Contentious Politics of Anti-Muslim Scapegoating in Myanmar, Journal of Contemporary Asia, 47:3, 353-375, 2017.

[13] KNUTERS, S., Political Buddhism and the Exclusion of Rohingya In Myanmar, Master's Thesis in Human Rights, Uppsala University. Norway, 2018.

[14] LEIDER, J., Rohingya: The History of a Muslim Identity in Myanmar. Southeast Asia Online Publication 2018.

[15] MASON, B. and BUCHMANN, D., ICT4 Refugee, GIZ, Berlin, Germany, 2016.

[16] MILTON, A.H., RAHMAN, M. (et. al), Trapped in Statelessness: Rohingya Refugees in Bangladesh, International Journal of Environmental Research and Public Health, MDPI, 2017.

[17] OCHA, Financial Tracking Service. 2019. Retrieved from: http://interactive.unocha.org/ publication/globalhumanitarianoverview/ (accessed on 09-12-2019).

[18] OHCHR. Darker and more dangerous: High Commissioner updates the Human Rights Council on human rights issues in 40 countries. Geneva: Office of the United Nations High Commissioner for Human Rights (OHCHR), 2017. Retrieved from: http://www.ohchr.org/EN/NewsEvents/Pages/DisplayNews.aspx?NewsID=22041 (Accessed on 30-12-2018).

[19] Oh, S., Surveillance and Control: The Encampment and Biometric Identification of Rohingya Refugees in Bangladesh. ISEAS Perspective 93. Singapore: ISEAS-Yusof Ishak Institute 2017.

[20] SIDDIQUI, H., Rohingya: The Forgotten People. Retrieved from: https://www.islamicity.org/ 2698/rohingya-the-forgotten-people/?AspxAutoDetectCookieSupport=1 Accessed on 1 December 2018.

[21] UNHCR, UNHCR-WFP, Joint Assessment Mission (JAM) Report 2019. 
[22] UNHCR, Connecting Refugees-How Internet and Mobile Connectivity can Improve Refugee Well-Being and Transform Humanitarian Action, 2016.

[23] VERNON, A., DERICHE, K. and EISENHAUER, S., Connecting refugees - how Internet and mobile connectivity can improve refugee well-being and transform humanitarian action. Geneva, Switzerland: UNHCR. 2016.

[24] WARSCHAUER, M., Technology and social inclusion: Rethinking the digital divide. Cambridge, MA: MIT Press, 2003.

[25] WFP, Rohingya Emergency Vulnerability Assessment-2, Cox’s Bazar, Bangladesh 2018.

[26] Needs and Population Monitoring (NPM), Government of Bangladesh, Round 13, November 2018 